DOI: 10.12737/article_5c920173c26696.31766666

УДК 658.512 .88

\author{
СТАНОВЛЕНИЕ ЛЕСНОГО МЕНЕДЖМЕНТА В УСЛОВИЯХ \\ РАЗВИТИЯ РЫНОЧНОЙ ЦИФРОВОЙ ЭКОНОМИКИ \\ кандидат технических наук, профессор Г.А. Прешкин ${ }^{1}$ \\ кандидат технических наук, профессор А.В. Мехренцев ${ }^{1}$ \\ кандидат педагогических наук, доцент С.Ф. Масленникова ${ }^{1}$ \\ доктор экономических наук, профессор В.М.Пищулов ${ }^{2}$ \\ 1 - ФБГОУ ВО «Уральский государственный лесотехнический университет», \\ г. Екатеринбург, Российская Федерация \\ 2 - ФБГОУ ВО «Уральский государственный экономический университет», \\ г. Екатеринбург, Российская Федерация
}

Нынешнее, затянувшееся на десятилетия депрессивное состояние лесного сектора экономики в Российской Федерации привело к диспропорции между социально-экономическим эффектом и затратами на поддержание природного потенциала лесов. Причина кроется в устаревшем стиле и методах управления лесными благами по всем их важнейшим функциям. В статье предлагается использовать положительный зарубежный опыт реализации принципов лесного менеджмента как ориентира для проведения коренных преобразований системы управления лесным сектором экономики. Лесной менеджмент - это эффективная система управления воспроизводимым природным объектом ценности в рыночной экономике. Он послужит началом креативного становления отечественного стиля рачительного пользования богатствами лесов для общественных нужд и российского населения. Условия развития цифровой рыночной экономики благоприятствуют применению методов менеджмента в лесном секторе. Предлагаются теоретико-методологические подходы к формированию лесного менеджмента, определено его место в системе экономических и управленческих наук, этапы формирования стратегии и тактики его поэтапного становления: кардинальное обновление нормативной базы и на её основе совершенствование методики количественной и стоимостной оценки эколого-технологически доступных ресурсов и полезных функций лесных экосистем с применением средств современных методов познания. Это разрешит проблему рисков проектного менеджмента в процессе становлении лесных бизнесов при постановке в известность размеров лесных региональных богатств как объектов управления оборотом лесных видов ресурсов во времени и пространстве с учетом затрат на их экономическое воспроизводство на территории земель государственного лесного фонда.

Ключевые слова: лесной менеджмент, лесные ресурсы, нормативы экономической оценки 


\title{
FORMATION OF FOREST MANAGEMENT IN CONDITIONS OF DIGITAL MARKET ECONOMY DEVELOPMENT
}

\author{
$\mathrm{PhD}$ (Engineering), Professor G.A. Preshkin ${ }^{1}$ \\ $\mathrm{PhD}$ (Engineering), Professor A.V. Mekhrentsev ${ }^{1}$ \\ $\mathrm{PhD}$ (Pedagogy), Associate Professor S.F. Maslennikova ${ }^{1}$ \\ DSc (Economics), Professor V.M. Pishchulov ${ }^{2}$ \\ 1 - FSBEI HE Ural State Forest Engineering University, Yekaterinburg, Russian Federation \\ 2 - FSBEI HE Ural State University of Economics, Yekaterinburg, Russian Federation
}

\begin{abstract}
The current depressed (for decades) state of the forest sector of the Russian economy has led to a disproportion between social and economic effect and cost of natural potential of forests maintaining. The reason lies in the outdated style and methods of managing the use of forest goods for all their essential functions. The article proposes to use positive foreign experience in implementing the principles of forest management as a guideline for carrying out fundamental changes in the environmental management system. Forest management is an effective system for managing a reproducible natural value object in a market economy. It will serve as the beginning of domestic style creative development of zealous use of forest wealth for public needs and the Russian population. The conditions for the development of a digital market economy favor the use of management methods in environmental management. Theoretical and methodological approaches to the formation of forest management, stages of formation of the strategy and tactics of its gradual formation are proposed: radical update of regulatory framework and improvement of methods for the quantitative and valuation of ecological and technologically accessible resources and useful functions of forest ecosystems for environmental planning using modern methods knowledge on its basis. This will solve the problem of maintaining sustainable management of forest businesses in the field of environmental management when notifying the size of regional forest wealth as the objects for managing the circulation of various types of forest products in time and space on the territory of the state forest fund lands.
\end{abstract}

Keywords: sustainable nature management, forest resources, standards of resources use efficiency

\section{Введение}

Социально-экономическое развитие лесного сектора экономики - это процесс затянувшегося периода крайне неэффективного управления национальными лесными богатствами России в условиях транзитивной рыночной экономики [1-3, 10 , $11,15]$. Лесные ресурсы являются важнейшим элементом системы экономических отношений общества. Их ценность в сфере финансов влияет на национальное и экономическое состояние страны. Ситуация, сложившаяся в Российской Федерации, привела к диспропорции между социальноэкономическим эффектом и затратами на поддержание природного потенциала стоимости национальных лесов. Требуется обновление структуры экономических механизмов лесопользования в виде инновационной модели устойчивого управления пользованием богатствами российских лесов на основе принципов цифровой рыночной экономики и лесного менеджмента, характерного для передовых лесных держав мира [3, 14, 27]. По определению Общества американских лесничих (1958) лесной менеджмент представляет собой «применение методов бизнеса и технических принципов лесоводства к управлению лесной недвижимостью» [20]. Следовательно, лесной менеджмент объективно присущ рыночной экономике, в нем строго учитываются законы рынка, он требует от менеджеров иной, более содержательной квалификации лесничего для управления ценностями лесных благ с использованием четырёх взаимосвязанных функций: планирования, организации, мотивации и контроля эффективности.

Целью исследования является обоснование места лесного менеджмента в системе экономических и управленческих наук для условий российской действительности. Основная цель лесного менеджмента в области планирования заключается в 
обеспечении гармоничного развития практической деятельности управляемых объектов по иерархии управления. Исходя из этого, основной задачей лесного менеджмента является создание, приведение в надлежащий порядок систему управления ценностями лесных благ и поддержание устойчивой эффективности многофункциональных лесных бизнесов.

Поставленные цели определили необходимость решений следующих взаимосвязанных задач исследования:

1. Обосновать методологическую схему построения системы лесного менеджмента лесными благами.

2. Сформулировать принципы лесного менеджмента.

3. Установить структурную взаимосвязь основных понятий, используемых в системе лесного менеджмента

Законодательством определен объект лесоустройства, им является лесничество (лесопарк) и на его территории финансирование работ по обустройству земель государственного лесного фонда (Project Management) осуществляется за счёт средств, выделяемых регионам из федерального бюджета. Порядок осуществления лесоустройства установлен Лесоустроительной инструкцией (2011 г.), которая разрабатывается и утверждается федеральным органом государственной власти в области лесных отношений. Существенным недостатком этой инструкции является низкий уровень общественного признания, её недостаточная легитимность как правового документа. Инструкция это руководящие указания, подробное наставление; свод правил для выполнения чего-либо. В настоящее время теоретические основы лесоустройства в части организационно-экономического планирования конкретного вида практического лесопользования деградированы, поскольку они утратили экономическую составляющую после введения в действие нового Лесного кодекса РФ (2006 г) [10]. Взамен былых хозяйственных объектов лесоустройства в рыночных условиях необходимы иные организационно-правовые формы организаций, составляющих круг основных видов лесных бизнесов (см. рис. 1), где объективно показано использо- вание методов лесного менеджмента (Forest Management) [2, 3, 8, 17].

Неудовлетворительное управление национальными лесными богатствами на протяжении более двадцати лет оборачивается системным кризисом лесоуправления в целом [15]. Выход из него авторы видят в разработке методологии и становлении современного лесного менеджмента как инструмента для достижения социо-экологоэкономического подъёма лесного сектора «зелёной» цифровой экономики в объектах хозяйствования крупных лесных природно-хозяйственных комплекcax и лесопромышленных кластерах [1-3, 7, 8, 11, 14, 17, 24].

Предмет и факторы формирования объектов лесного менеджмента. Если общий менеджмент - это профессионально осуществляемое управление любой хозяйственной (социальноэкономической) деятельностью организации (предприятия), направленной на получение дохода на основе принципов эффективного использования ограниченных ресурсов и правильного социальноэколого-ориентированного поведения людей, то своеобразие лесного менеджмента выражают принципы экологического управления. Считается, что основной задачей лесного менеджмента является созидание национального природного капитала, приведение его в надлежащий порядок и управление его экономико-правовой квотой постоянного пользования посредством возможностей лесных бизнесов на базе государственного или государственно-частного предпринимательства $[8,15]$.

Какое место должен занять лесной менеджмент в системе экономических и управленческих наук? Почти век тому назад в развитие передовых идей лесоустройства и традиционного лесоуправления, выдающийся деятель лесной науки проф. М.М. Орлов на основе научных трудов французского учёного экономиста в сфере менеджмента А. Файоля, предложил применительно к российской системе хозяйствования новую, научно обоснованную модель устойчивого управления пользованием богатствами лесов. Однако в то время она не нашла поддержки у властей для внедрения в практику лесоуправления в России $[10,16]$. 
Обеспечивать эколого-экономический успех в рыночных условиях рачительное пользование и воспроизводство благ лесов позволяет менеджерам лесного дела (лесничему как государственному служащему) мастерство, умения и знания основ экономики и организации лесного бизнеса во всех сферах хозяйственной деятельности, если они на научной основе прилагают свои управленческие усилия для правильного ведения лесного бизнеса. Такой подход к лесоуправлению на основе идей проф. М.М. Орлова вновь актуален на ином, более совершенном научном уровне и по праву должен занимать в системе экономических и управленческих наук достойное место для коренной трансформации российской системы обучения основам искусства лесоуправления (Operational Management) [9].

Неудовлетворительное управление национальными лесными богатствами на протяжении более двадцати лет оборачивается системным кризисом лесоуправления [15]. Выход из него авторы видят в разработке методологии и становлении современного лесного менеджмента как актуального инструмента для достижения социо-экологоэкономического подъёма лесного сектора «зелёной» цифровой экономики в объектах хозяйствования крупных лесных природно-хозяйственных комплексах и лесопромышленных кластерах $[2,7,11,15,17$, 24].

Целью исследования выступает также анализ проблем и выявление перспектив развития лесного менеджмента как малоисследованной составляющей региональной цифровой экономики с учетом современных рыночных условий и глобализации. Поставленная цель предопределила на будущее необходимость решения следующих задач $[2,7,8$, 11, 16, 19, 21]:

- определить сущность лесного менеджмента, проблемы его становления в развивающейся «зелёной» цифровой рыночной экономике;

- определить миссию, стратегическую цель развития лесного сектора экономики и роль системы лесного менеджмента в нём, наметить этапы разработки политики лесного менеджмента в регионах;
- обосновать необходимость введения на современном этапе методологии лесного менеджмента в лесной сектор экономики.

Стоит отметить, что в утверждённой в России «Стратегии развития информационного общества РФ на 2017-2030 годы» дано следующее определение цифровой экономики: «Цифровая экономика это хозяйственная деятельность, в которой ключевым фактором производства являются данные в цифровом виде, обработка больших объемов и использование результатов анализа которых по сравнению с традиционными формами хозяйствования позволяют существенно повысить эффективность различных видов производства, технологий, оборудования, хранения, продажи, доставки товаров и услуг» [12]. Объектом лесного менеджмента является организация управления больших объёмов экономической информации о разнородных по своей природе факторах (экономических, социальных, экологических, технологических), для эффективного удовлетворения организациями насущных потребностей рынков и местного населения в лесобумажных товарах и полезностях лесов [3, 10, 11, 25].

Экономические факторы являются важнейшими, однако они отражают лишь финансовые интересы организаций лесного бизнеса. Для их основного структурного звена - субъекта хозяйствования - этими интересами являются: финансовая самостоятельность, коммерческий расчет, интернализация внешних эффектов (платность экосистемных услуг) и др. [18, 25, 26].

Социальные факторы формирования объектов лесного менеджмента учитывают, прежде всего, уровень занятости трудоспособного населения, обеспеченность жильём, транспортным, коммунальным и социально-культурным обслуживанием жителей, порой отдаленных лесных населённых пунктов от центральных административнохозяйственных центров, поддержание возможностей для духовного и культурного развития детей и взрослых [5, 18, 19]. В последнее время с позиции интересов данного фактора актуализируется категория «человеческий капитал», в том числе в социальной среде лесного сектора экономики. Медленно растёт роль внешних эффектов от пользования невесомыми функциями лесов на усиление важно- 
стей развития социального фактора в системе удовлетворения потребностей в рекреации, туризме, ассимиляции вредных веществ [1, 5, 10, 17,18, 23].

Экологические факторы отражают интересы устойчивого развития лесопользования и лесоводства. Принципы постоянства лесопользования и сохранения биоразнообразия, депонирование углерода для стабилизации состава атмосферного воздуха являются ведущими в организации лесного сектора экономики и стратегии его развития $[2,4$, 9, 18].

Технико-технологические факторы отражают характер и специфические черты труда в лесном секторе экономики, они значимо влияют на процессы его разделения по сферам деятельности, кооперации, повышения производительности. Формирование объектов управления по техникотехнологической общности трудовой деятельности определяет основное содержание потребности лесовыращивания при создании крупных комплексных природно-хозяйственных кластеров на основе государственно-частного партнёрства [2, 9-11, 27].

Действие вышеназванных факторов интегрирует собой организационныцй фактор, который определяет базовую количественную и качественную характеристику объекта управления, его конкретное выражение и внутренние структурные связи $[13,23]$.

В новой экономике ведущим фактором в формировании объектов лесного менеджмента является экологический фактор, учитывающий особенности в организации устойчивого развития лесопользования и всей системы ведения лесного хозяйства $[4,21]$. Лесоводство, в концентрированном виде выражающее данный фактор, является научной основой организации лесохозяйственного производства лесных ресурсов (рис. 2).

Предметом лесного менеджмента является наука о лесоуправленческих экологоэкономических отношениях, возникающих в разнообразных масштабах использования и устойчивого воспроизводства лесных ресурсов. Так, лесной менеджмент в широком смысле выражает становление эколого-экономического управления в лесном секторе экономики страны посредством системы формирования и реализации лесной политики государства. Лесной менеджмент в узком смысле определяет система лесоуправления, выражающая интересы субъектов лесной собственности и условия устойчивого ведения лесного бизнеса.

В методологическом плане на формирование лесного менеджмента из экономических наук непосредственное влияние оказывает экономика природопользования и ее дочерняя наука - лесная цифровая экономика.

Объектом лесной экономики является устойчивое развитие воспроизводства и использования лесных ресурсов. Узловая проблема стратегии устойчивого развития - формирование социальноэкономических условий рачительного пользования лесных благ бизнесом в пределах хозяйственно допустимой квоты от продукционного потенциала экосистем. С этих позиций биосфера рассматривается не как неисчерпаемый источник материальных ресурсов природы, а как естественный фундамент жизни, сохранение которого во времени и пространстве - обязательное условие социальноэкономического развития. В данном контексте определяющая роль отводится экологической безопасности $[1,18,20]$. Речь идет о кардинальном пересмотре ценностных установок современного лесного менеджмента, под влиянием которого должно произойти основательное изменение парадигмы экономической эффективности воспроизводства лесных благ и результативности производства лесных товаров. 


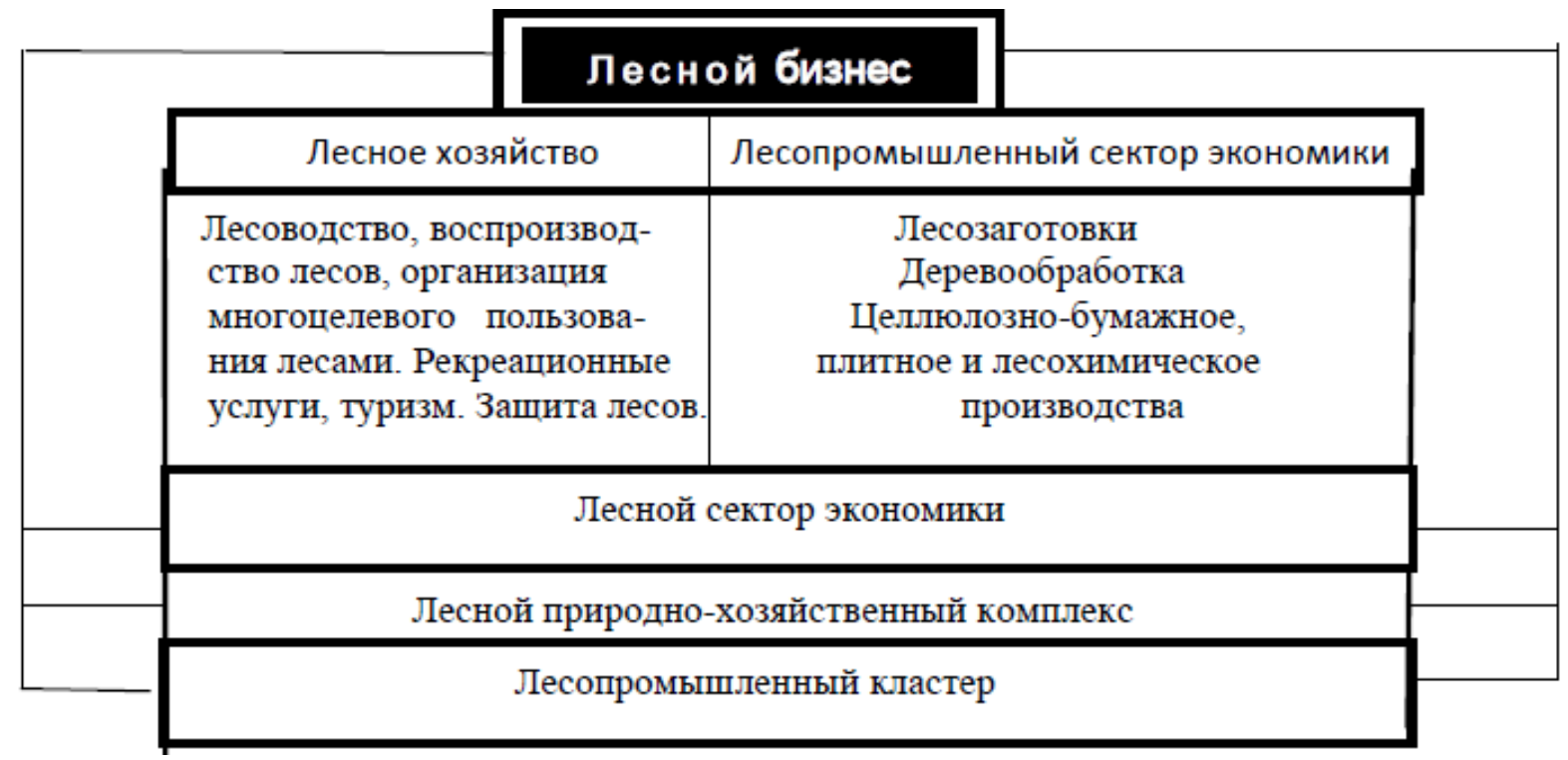

Рис. 1. Структурная взаимосвязь основных понятий в системе лесного менеджмента

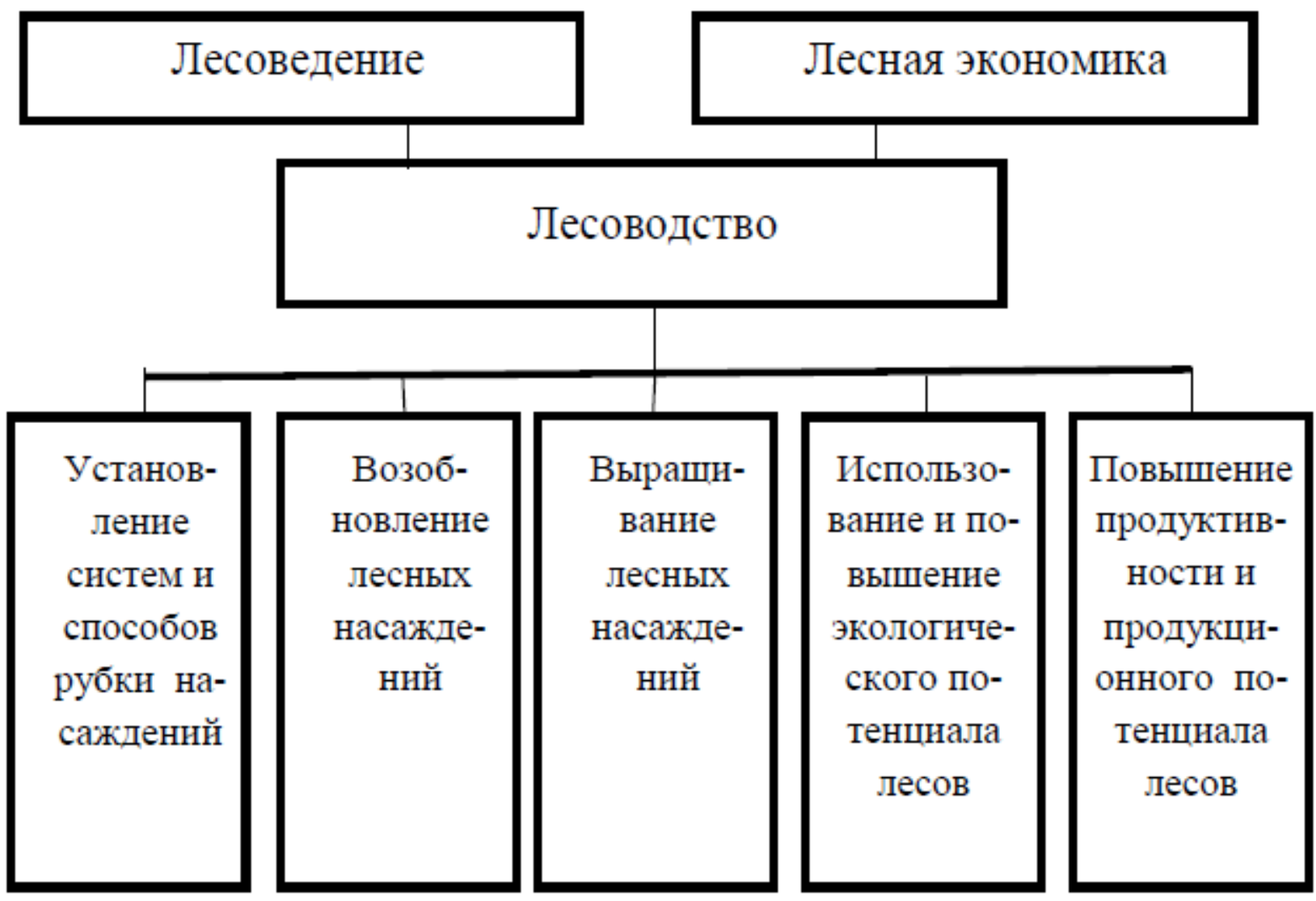

Рис. 2. Трансформация лесоведения и лесной экономики в лесоводство

Предлагается на основе структурной экономико-технологической и институциональной перестройки лесоуправления осуществить переход к устойчивому развитию экологизации производств, в частности, в лесном секторе экономики, где вопросы развития решаются на основе иннова- 
ционной модели управления лесопользованием [14]. Эффективность перестройки структуры управления с позиции интересов устойчивого развития рассматривается как уровень достижения (или превышения) научно обоснованной и социально целесообразной нормы потребностей $[1,2,10,11,26]$. Структуризация потребностей в аспекте постиндустриального развития (когда наступает превосходство сектора услуг, особенно тех, которые определяют воспроизводство человеческого капитала) и, соответственно, правильная структуризация производства - главная линия роста эффективности экономики лесопользования. Для достижения устойчивого развития его неотъемлемую часть должна составлять экономическая защита окружающей среды с использованием информации мониторинга цен на лесобумажные товары во всех странах, чтобы отражать страновую «экологическую стоимость» их производства и выражать её рефлективностью на стоимостях национальных лесобумажных товаров $[1,2,18]$.

Сложившиеся стереотипы мышления, базирующиеся на убеждении в том, что нынешние экологические затруднения можно разрешить за счет внедрения ресурсосберегающих и малоотходных технологий, совершенствования производственных процессов и т. п. являются несостоятельными. Такого рода представления не учитывают того факта, что главное в достижении устойчивого развития зависит от ценностных ориентаций человека и его отношения к природе $[1,8,11,19,21]$. Следует признать, что чисто технического или технологического пути решения социально-экологических проблем не существует. Энерго и ресурсосберегающие технологии, хотя и приносят несомненный положительный эффект, но совершенно недостаточны для преодоления экологического кризиса $[1,22]$. Люди добровольно не откажутся от своего экологического благополучия, от научно обоснованной и социально целесообразной нормы потребления экологических благ. Необходима воля государства в обеспечении стабильности этих норм, иначе последует наращивания всех видов капитала, за исключением одного - экологического, только он ограничен в приращении количества и качества ресурсов окружающей среды естественными природно-климатическими факторами.

Новая экономика - это технология жизни человека, основанная на 5 базовых принципах, сформулированных В. Смитом и Д. Канеманом - лауреатами Нобелевской премии по экономике в 2002 г. [4]. И, чем эти принципы эффективнее реализуется, тем богаче экономика и более содержательна жизнь человека, да и сам человек. В мире люди не могут быть все равны, но духовное богатство мировой цивилизации составляет общее достояние. Примат духовного богатства над материальным - признак нового качества человека и его потребностей. Человеческие потребности с учетом экологических ограничений и этических норм - исходный пункт устойчивого развития. Смещение экономических интересов в сторону духовного развития человека - один из главных принципов новой экономики, необходимая предпосылка решения экологических проблем. Но чтобы это изменение произошло, необходимо изменить самого человека, обеспечив ему достойный уровень качества жизни как исходную базу его духовного развития $[3,4,21,23]$. Вместе с тем фундаментальные незаменимые свойства общественного блага возвышают человека над благами частными.

Социальная система целенаправленного воспроизводства чистого общественного блага способна кардинально изменить содержание экономических отношений. Самое главное в развитии зеленой экономики - разрешение противоречия между частным и общественным интересом к благам окружающей среды обитания [1, 21-23]. Общественное благо реализуется через творческую деятельность каждого человека, свободную реализацию его способностей и талантов. Интерес всех членов общества в полезности общественных благ, переведенный в «коммерческое русло», обеспечивает их устойчивое воспроизводство. В справедливом обществе соблюдается пятый принцип новой экономики - рациональное природопользование, ценность которого признается не только человеком экономическим, но и экологическим, этическим, эстетическим [3, 8, 14, 16, 20]. Справедливый социум - это общество благосостояния, которое далеко не исчерпывается материальным благополучием. Невозможно рассматривать общественное благо- 
состояние вне удовлетворения экологических, этических и эстетических потребностей. Благо, их удовлетворяющее, имеет все черты чистого общественного товара. Вопрос устойчивого развития лесной экономики - это проблема самого человека, мотивации людей и их отношения друг к другу и к природе. Ее корни уходят в проблему гуманизации человека и его поведения. Человексущество биодуховное, «био» имеет физическое измерение, духовность - измерение нравственное. Наличие духовного начала выделяет нас из окружающего мира (природы), но не отделяет от него. Духовная составляющая человека формирует его сущность, которая по отношению к остальной природе имеет одно отличие - совесть, удивительное и драгоценное свойство человека. Закон совести гласит: «Во всем, как хотите, чтобы с вами поступали люди, так поступайте и вы с ними, ибо в этом закон и пророки» [5]. С этих позиций мораль становится не только самоцелью, но и определяющим фактором человеческого развития, формирующего адекватную социальную среду и систему самостоятельно ограниченных потребностей. Следовательно, высшие духовные ценности реализуются с помощью этики, которая в последнее время все больше и больше становится институциональной, так или иначе, воздействуя на поведение экономического человека в деловой среде персонала лесного менеджмента [4, 22].

Итак, основная цель лесного менеджмента в области практической деятельности заключается в том, чтобы обеспечить гармоничное развитие управляемого объекта по иерархии управления. Это означает, что все элементы лесной сферы экономики как объекты управления, включая лесного менеджера, должны функционировать согласованно и эффективно в составе контура организационной структуры, приведенной на рисунке 3 .

На рис. 3 показаны основные этапы формирования системы лесного менеджмента, без которого невозможно решение задач Государственной программы развития лесного комплекса России на период до 2020 года:

- использование международного опыта и знаний для актуализации национальной политики, становления системы лесного менеджмента в лесном секторе цифровой экономики [12];

- развитие национального лесного законодательства и формирование адаптивной системы экономических инструментов, необходимых для активного становления лесного менеджмента как инструмента развития;

- обеспечение политических и экономических интересов России при реализации международных документов в области лесного хозяйства;

- использование возможностей государственных финансовых ресурсов для решения актуальных проблем пользования лесами и их воспроизводства, экономико-технологического развития лесной науки и лесотехнического образования для формирования специалиста инженера - менеджера, востребованного в сфере лесных бизнесов;

- привлечение в государственный лесной сектор экономики инноваций и частных инвестиций путем развития взаимовыгодного двустороннего сотрудничества для становления лесного менеджмента в условиях рыночной цифровой экономики [6].

Важнейшей составляющей успеха в управлении национальными лесными ресурсами является создание комплекса технических регламентов как законодательных установлений правовой основы лесных отношений в системе лесного менеджмента. Это позволит государственному служащему - лесничему повысить эффективность использования экономико-правового ресурса о лесных благах лесничества для многофункциональных целей успешного хозяйствования. Ключевым звеном в лесном менеджменте как организационно-управленческом механизме возникает качественно новая фигура государственного лесного менеджера, наделённого правами и обязанностями, ответственного за эффективность решения социо-эколого-экономических (управленческих) задач «зелёной» цифровой экономики и роста лесного дохода на территории лесничества (лесопарка). В его деятельности ведущим фактором в формировании объекта лесного менеджмента явится экологический фактор, учитывающий особенности организации устойчивого развития экологизированного лесопользования на принципах новой экономики [1-3, 7-12]. 


\section{Результаты исследований}

Лесной менеджмент в условиях социальноориентированной рыночной цифровой экономики и цифровых информационных систем передачи и применения современной актуальной информации о внутренних и внешних параметрах системы управления необходим как экономический инструмент для успешного ведения современных лесных бизнесов [21-23]. Одной из важнейших проблем становления лесного менеджмента является формировании систем новых знаний о количественных и качественных таксационных нормативах целевых технологически доступных лесных товаров потребительского выбора, содержащихся в эксплуатационных и защитных лесах объектов лесоуправления $[10,13]$. Они необходимы для постановки в извест- ность технологически доступные древесные ресурсы для оценки количества и качества целевых лесопродуктов, которые они содержатся в эксплуатационных древостоях, информация о которых отсутствует для применения в системе лесного менеджмента для текущего и перспективного планирования лесопользования с применением современных методов познания. Следует отметить, что различия основ теории общего и лесного менеджмента с прагматической точки зрения нуждаются в подкреплении методологии принятия управленческих решений с применением современных методов познания, что явится предметом последующих обсуждений проблем становления лесного менеджмента и в условиях развития рыночной цифровой экономики.

\section{Управление как функция (особое свойство, снла, слабость) организаци-} онных снстем обеспечнвать свою жнзнедеятельность

\section{Управленне как наука об управленческих отношениях, возникаюших в} результате воздействия управляюшей системы на управляемую систему на основе цифровых ннформацнонных прямых н обратньх связей

\section{Лесной менеджмент как выражение высокоэффективного типа бнзнеса на прннципах новой экономики}

\section{Лесной менеджер как новый тип профессин управленца- организатора бнзнеса в лесном секторе экономнкн}

Рис. 3 Лесной менеджмент как сфера управления в условиях социально-ориентированной рыночной экономики

\section{Выводы}

Проблема совершенствования инновационного управления ценностями лесных благ в условиях цифровой рыночной экономики в общем виде не решена. Её решение связано с созданием концептуальных основ инновационного преобразования структуры управления лесным сектором экономики и наличием воли государства к переменам в мето- дах управления государственным лесным природным капиталом в полном соответствии условиями рыночных реальностей. Многолетняя практика и апробированная методология инновационного управления пользованием и воспроизводством лесных благ, характерных для передовых лесных держав с рыночным стилем экономики ассоциируется с необходимостью внедрения в России лесного ме- 
неджмента. Применение методов лесного менеджмента менеджерами нового поколения при коренной перестройке структуры и системы управления лесным хозяйством и лесопромышленным освоением лесных ресурсов позволит реабилитировать социально-экономическую эффективность российских лесов как национального богатства.

Таким образом, теоретико-методологический анализ и аргументы о необходимости неотложных преобразований структуры управления ценностями лесных национальных богатств и методов управления ими с применением методов лесного менеджмента в условиях зелёной цифровой рыночной экономики позволит восстановить достойный вклад лесного сектора в эффективность экономики регионов и страны в целом.

\section{Библиографический список}

1. Белик, И. С. Оценка и диагностика эколого-экономической безопасности территорий: моногр. / И. С. Белик. - Екатеринбург, 2008.

2. Безрукова, Т. Л. Концепция природно-хозяйственного комплекса / Т. Л. Безрукова, Г. А. Прешкин, Г. Л. Нохрина // Актуальные направления научных исследований XXI века: теория и практика: сб. науч. тр. междунар. науч.-практ. конф. - Воронеж, 2014. - № 3. - Ч. 3. - С. 394-399.

3. Выводцев, Н. В. Цели и задачи лесоустройства в новой концепции управления лесным хозяйством // Проблемы региональной экологии: матер. Второй всерос. конференции. - Новосибирск : Изд-во СО РАН, 2000.

4. Деминг, Э. Новая экономика. The new Economics for Industry, Government, Education: моногр. /

Э. Деминг. - М: Эксмо. 2006.

5. Святое Евангелие (с приложениями). - Клин : Христианская жизнь. 2006.

6. Казаков, Н. В. Методы учёта древостоев лесосек и мониторинга произведённой продукции / Н. В. Казаков, П. Б. Рябухин // Лесной журнал. - 2017. - № 5. - С. 103-109.

7. Ковалевич, Д. А. Сегодня конкурируют не компании, а кластеры / Д. А. Ковалевич. - URL: www.atomic-energy.ru/interviews/2012/17/31034.

8. Кожухов, Н. И. Концептуальные подходы к формированию лесопромышленных кластеров в России / Н. И. Кожухов, Н. П. Кожемяко, А. А. Фитчин // Лесотехнический журнал. - 2017. - № 3. C. 236-253.

9. Лесное управление: моногр. / А. В. Неверов [и др.]. - Минск : Печатковая школа, 2014.

10. Управление проектами лесопользования - альтернатива лесоустройству / А. В. Мехренцев [и др.]. // Аграрный вестник Урала. - 2016. - № 11 (152). - С. 41-45. - URL: www.avu.usaca.ru.

11. Организация устойчивого лесопользования в Красноярском крае / [В. А. Соколов и др.] ; отв. ред. И.В. Семечкин; Ин-т леса им. В.Н. Сукачева СО РАН, Сиб. меж. ин-т леса, Красноярское рег. обществ. экодвижение «Друзья сибирских лесов». - Новосибирск : Изд-во СО РАН, 2009.

12. Указ Президента РФ от 9 мая 2017 г. № 203 «О стратегии развития информационного общества в Российской Федерации на 2017-2030 годы». URL ttp://www.consultant.ru/document/cons_doc_LAW_216363/.

13. Прешкин, Г. А. Нормативы оценки лесных благ: проблемы, решения: моногр. / Г. А. Прешкин. Екатеринбург, 2011.

14. Прешкин, Г. А. Экономические механизмы перевода лесопользования на инновационную модель устойчивого управления / Г. А. Прешкин // Известия Оренбургского гос. аграрн. ун-та. - 2014. - № 2 (46). C. 229-232.

15. Степанов, С. В. Направления и механизмы государственного участия в развитии лесного сектора Российской Федерации / С. В. Степанов // Лесной вестник. - 2014. - № 3. - С. 50-55.

16. Орлов, М. М. Лесоуправление / М. М. Орлов. - М. : Лесн. пром-сть, 2006. 
17. Ферова, И. С. Кластерная модель как инструмент устойчивого инновационного развития Красноярского края / И. С. Ферова, Е. Н. Таненкова // Управленец. - 2015. - № 5(57). - С. 58-63.

18. Altunina, T. M. Information as an economic resource / T. M. Altunina, G. A. Preshkin // SGEM conf. on political sciences, law, finance, economics \& tourism: Intern. conf. proceeds (Economics \& tourism), Vol. III. Albena. Bulgaria. 2014. pp. 285 -291.

19. Chen S., Shahi C., Chen H., etc. Economic analysis of forest management alternatives: Compositional objectives, rotation ages, and harvest methods in boreal forests // Forest Policy and Economics. 2017. Vol. 85. Part 1. pp. 124-134.

20. Davis, L. S. (2008) Forest Management. Textbook. URL: Lisalill.com/ebookpage/116657Forest=Management.

21. Deal R., Smith N., Gates J. Ecosystem services to enhance sustainable forest management in the US: moving from forest service national programmes to local projects in the Pacific Northwest // Forestry.2017. Vol. 90. Essie 5. pp. 632-639.

22. Eriksson L., Bjorkman C., Klapwijk M. General public acceptance of forest risk management strategies in Sweden: Comparing three approaches to acceptability // Environment and Behavior. 2018. Vol. 50. Essie 2. pp. $159-186$.

23. Lexer M., Bugmann H. Mountain forest management in a changing world // European Journal of Forest Research. 2017. Vol. 136. Essie 5-6. pp. 981-992.

24. Liubachyna A., Bubbico A., Secco L., etc. Management goals and performance: clustering state forest management organizations in Europe with multivariate statistics // Forests. 2017. Vol. 8. Essie 12. Paper \# 504.

25. Mollmann, T., Moehring B. A practical way to integrate risk in forest management decisions // Annals of Forest Science. 2017. Vol. 74. Essie 4. pp. 137-145.

26. Mobtaker A., Ouhimmou M., Ronnqvist M., etc. Development of an economically sustainable and balanced tactical forest management plan: a case study in Quebec // Canadian Journal of Forest Research. 2018. Vol. 48. Essie 2. pp. 197-207.

27. Jovanovič M., Milanovič M., Zorn M. The use of NDVI and CORINE land cover databases for forest management in Serbia // Acta Geographica Slovenica-Geografski Zbornik. 2018. Vol. 58. Essie 1. pp. 109-123.

\section{References}

1. Belik I. S. Otsenka i diagnostika ecologicheskoy i economicheskoy bezopasnosti territoriy: monografia [Assessment and diagnosis of ecological and economic security of territories: monograph] Ekaterinburg, USTU-UPI Publ., 2008.

2. Bezrukova T. L., Preshkin G. A., Nokhrina G. L. Kontseptsia prirodno-ekonomicheskogo kompleksa [Concept of natural-economic complex // Actual directions of scientific researches of the XXI century: theory and practice: Intern. conf. proceeds] Voronezh, 2014, no. 3, part 3, pp. 394-399.

3. Vyvodtsev N.V. Tseli $i$ zadachi lesoustroistva $v$ novoy koncepzii upravlenia lesnym khozjistvom [Goals and tasks of new conception of forest management // Problems of regional ecology: The Second all-Russian conference proceeds] Novosibirsk, Siberian branch of RAS. 2000. pp. 251-252.

4. Deming, Edward. Novaja ekonomika [New economy. The new Economics for Industry, Government, Education: monograph] Moscow, Esmo Publ., 2006.

5. Svijatoe evangilie s prilozhenijami [The Holy gospel (with annexes)] Klin, Christian life Publ., 2006.

6. Kazakov N. I. Ryabukhin P. B. Metody ucheta drevostoev i monitoringa proizvedennoy produktsii [Methods of accounting of forest stands of felling and monitoring produced goods]. Lesnoy zhurnal, 2017, no. 5, pp. 103-109.

7. Kovalevich D. A. Segodnya konkurirujut ne kompanii, a klastery [Today not companies are competing, but clusters]. URL:www.atomic-energy.ru/interviews/2012/17/31034. 
8. Kozhukhov N. I., Kozhemyako N. P. and Phitchin A. A. Kontseptual'nye podkhody k formirovaniju lesopromyshlennyh klasterov $v$ Rossii [Conceptual approaches to the formation of a forestry cluster in Russia]. Lesotekhnicheskiy zhurnal, 2017, no. 3, pp. 236-253.

9. Lesnoe upravlenie: monografiya. A.V. Neverov, i drugie [Forest management: monograph. A.V. Neverov., etc] Minsk, Pochatkova schkola, 2014.

10. Mekhrentsev A. V., Preshkin G. A., Rusin, K. I., etc. Upravlenie proektami lesopolzovania -al'ternativa lesoustroistvu [Project forest management as alternative to forest organization] Izvestija Ural'skogo gosudarstvennogo agrarnogo universiteta - Proceedings of the Urals state agrarian university, 2016, no.11, pp. 41-45. URL: www.avu.usaca.ru.

11. Organizatsiy ustoychivogo lesopol'zovaniy v Krasnojarskom kraie [Sustainable forest management in Krasnoyarsk region] Institute of forests named after V.N.Sukatchev. Novosibirsk: Siberian branch of RAS. 2000.

12. Ukaz Prezidenta RF ot 9 May 2017. № 203 «O strategii razvitiy informatsionnogo obtshestva v Rossiyskoy Federatsii na 2017-2030 gody».[Directive of the Russian Federation President at May 9, 2017. № 203: "About the development strategy of society information in the Russian Federation during 2017-2030 years"] URL: http://www.consultant.ru/document/cons_doc_LAW_216363/

13. Preshkin, G. A. Normativy otsenki lesnykh blag: problemy i resheniya: monografiya [Normal of valuation of forest benefits: problems and solutions: monograph] Ekaterinburg, 2011.

14. Preshkin G. A. Ekonomicheskie mechanizmy perevoda lesopolzovania na innovatsionnuyu model ustoichivogo upravleniya [Economic mechanisms of transfer of forest management to an innovative model of sustainable management] Izvestija Orenburgskogo gosudarstvennogo agrarnogo universiteta - Proceedings of Orenburg state agrarian university, 2014, № 2 (46), pp. 229-232.

15. Stepanov S. V. Napravleniya I mekhanizmy gosudarsvennogo uchastiya v razvitii lesnogo sektora Rossiiskoj Federatsii [Directions and mechanisms of public participation in the development of the forest sector of the Russian Federation] Lesnoy Vestnik - Forest Bulletin, 2014, №. 3, pp. 50-55.

16. Orlov M. M. Lesnoje upravlenie [Forest Management] - Moscow, Forest Industry Publ., 2006.

17. Ferova I.S., Tanenkova E.N. Kklasternaja model kak instrument ustojchivogo innovatsionnogo razvitija Krasnojarskogo kraja [Klaster model as instrument of sustainable development of Krasnojarsk region] // Manager. 2015. № 5(57). C. 58-63.

18. Altunina T.M., Preshkin G.A. Information as an economic resource / SGEM conf. on political sciences, law, finance, economics \& tourism: Intern. conf. proceeds (Economics \& tourism), vol. III, Albena. Bulgaria, 2014, pp. $285-291$.

19. Chen S., Shahi C., Chen H., etc. Economic analysis of forest management alternatives: Compositional objectives, rotation ages, and harvest methods in boreal forests // Forest Policy and Economics, 2017, vol. 85, part 1, pp. 124-134.

20. Davis, L.S. (2008) Forest Management. Book. URL: Lisalill.com/ebookpage/116657-Forest=Management.

21. Deal R., Smith N., Gates J. Ecosystem services to enhance sustainable forest management in the US: moving from forest service national programmes to local projects in the Pacific Northwest // Forestry, 2017, vol. 90, part 5, pp. 632-639.

22. Eriksson L., Bjorkman C., Klapwijk M. General public acceptance of forest risk management strategies in Sweden: Comparing three approaches to acceptability // Environment and Behavior, 2018, vol. 50, part 2, pp. 159-186.

23. Lexer M., Bugmann H. Mountain forest management in a changing world // European Journal of Forest Research, 2017, vol. 136, part 5-6, pp. 981-992.

24. Liubachyna A., Bubbico A., Secco L., etc. Management goals and performance: clustering state forest management organizations in Europe with multivariate statistics // Forests, 2017, vol. 8, part 12, paper \# 504.

25. Mollmann, T., Moehring B. A practical way to integrate risk in forest management decisions // Annals of Forest Science, 2017, vol. 74, part 4, pp. 137-145. 
26. Mobtaker A., Ouhimmou M., Ronnqvist M., etc. Development of an economically sustainable and balanced tactical forest management plan: a case study in Quebec // Canadian Journal of Forest Research, 2018, vol. 48, part 2, pp. 197-207.

27. Jovanovič M., Milanovič M., Zorn M. The use of NDVI and CORINE land cover databases for forest management in Serbia // Acta Geographica Slovenica-Geografski Zbornik, 2018, vol. 58, part 1, pp. 109-123.

\section{Сведения об авторах}

Прешкин Герман Алексеевич - кандидат технических наук, профессор, ФГБОУ ВО «Уральский государственный лесотехнический университет», г. Екатеринбург, Российская Федерация; е-таil: preshkin.german@yandex.ru.

Мехренщев Андрей Вениаминович - кандидат технических наук, профессор ФГБОУ ВО «Уральский государственный лесотехнический университет», г. Екатеринбург, Российская Федерация.

Масленникова Светлана Федоровна - кандидат педагогических наук, доцент ФГБОУ ВО «Уральский государственный лесотехнический университет», г. Екатеринбург, Российская Федерация.

Пищулов Виктор Михайлович - доктор экономических наук, профессор ФБГОУ ВО «Уральский государственный экономический университет», г. Екатеринбург, Российская Федерация.

\section{Information about authors}

Preshkin German Alekseevich - PhD (Engineering), Professor, FSBEI HE "Ural State Forest Engineering University", Yekaterinburg, Russian Federation; e-mail: preshkin.german@yandex.ru.

Mekhrentsev Andrei Veniaminovich - PhD (Engineering), Professor, FSBEI HE "Ural State Forest Engineering University", Yekaterinburg, Russian Federation.

Maslennikova Svetlana Fedorovna - PhD (Pedagogy), Associate Professor of FSBEI HE "Ural State Forest Engineering University", Yekaterinburg, Russian Federation.

Pishchulov Viktor Mikhailovich - DSc (Economics), Professor of FSBEI HE "Ural State University of Economics", Yekaterinburg, Russian Federation. 